\title{
Article
}

\section{Can Amateur Football Help Players Meet the Requirements for a Healthy Lifestyle? A Case Study}

\author{
Javier Fernandez-Rio ${ }^{1, *}$, Alejandro Antón-Candanedo ${ }^{1}$ and Jorge García-Del Bosque ${ }^{2}$ \\ ${ }^{1}$ Department of Educational Sciences, University of Oviedo, Oviedo 33003, Spain; \\ candanedo91@gmail.com \\ ${ }^{2}$ Llaranes Club de Futbol, Avilés, Spain; delbosque_06@hotmail.com \\ *Correspondence to: javier.rio@uniovi.es
}

\begin{abstract}
The main goal of the study was to obtain objective measures of the impact of a complete pre-season of amateur football on the players' physical activity parameters. 17 amateur football players $(24.47 \pm 4.53$ years $)$ enrolled in the same team agreed to participate. They were asked to wear one accelerometer on the right hip during each training practice. Moderate-to-Vigorous physical activity (MVPA), steps and metabolic-equivalent (METs), among other parameters, were obtained and analyzed. Results showed that players spent an average $54.86 \%$ of each training session in MVPA levels, for a total of 100.33 minutes every week ( 3 training sessions per week). Therefore, this group of amateur football players did not meet the requirements to obtain health benefits from their physical activity program: amateur football. This finding could be considered noteworthy because there are thousands of adults worldwide who play amateur football to maintain a healthy lifestyle. They should be aware that their weekly training load is not enough to help them meet the necessary requirements. They either need more practice time (90-minute sessions) or more sessions. The pre-season training program was rated as "somewhat hard" by the participants, and quadriceps and hamstrings were mentioned as the most exerted muscles.
\end{abstract}

Keywords: accelerometers; MVPA; health; adults

\section{Introduction}

Physical activity has been recognized as a key factor to achieve good health. Adults should meet at least one of these criteria to obtain health benefits $[1,2,3]$ : (1) 150 minutes a week of moderate-to-vigorous (MVPA) physical activity (2) 30 minutes of moderate-intensity physical activity on at least 5 days a week, (3) 20 minutes of vigorous-intensity physical activity on at least 3 days a week, or (4) 600 metabolic equivalent (MET)-minute per week. Unfortunately, $2 / 3$ of adults and almost $80 \%$ of young people do not reach the minimum recommended [4]. This has been directly linked to health problems such as obesity, hypertension, diabetes, cardiovascular disease, coronary heart disease, cancer or stroke, and, consequently, a reduction of life expectancy [5]. However, recent surveys have found an increase in adults' leisure time physical activity, and this includes sport participation, for example football [6]. The effects of football training on individuals' health has been compared to other types of physical activity such as running, swimming or cycling, but the adherence to these programs based on aerobic exercise and repetitive activities is relatively low, and many participants suspend the activity after a few months for reasons that include boredom or tiredness [7]. There seems to be a need to develop more enjoyable training programs than can elicit greater adherence, and football could be one of them.

Football/Soccer is considered the most popular sport, because millions of individuals practice it worldwide. However, individual's involvement and participation in soccer can be very different depending on the way it is organized and the goals or objectives of its participants. Bennike et al [8] distinguished three types of football organization in Denmark: (a) 
Professionalism: football as a job where professional organizations rule the sport, and the main goal of its participants is to improve skills and tactics, (b) Leisure: football as a hobby where non-profit organizations rule the sport and the main goal of its participants is also to improve skills and tactics, and (c) Exercise: football as a means for health, ruled also by nonprofit organizations and the main goal of its participants is to improve their fitness. This last type is called Football Fitness and it is increasingly becoming more and more popular in Denmark to maintain individuals' health. The second type of football (leisure) has also been called recreational, and it is based on small sided games (i.e., 4vs4, 5vs5) played in reduced pitches with different number of players [7]. Different studies have showed that recreational football can produce improvements in VO2 max, body fat, blood pressure, bone health, and cardiac function $[9,10,11,12]$. There exists another type of football organization that falls between the categories of professional and recreational/leisure football with thousands or even millions of participants worldwide: amateur football. It has all the characteristics of professional football, but players and coaches cannot make a living out of it.

In a survey between young adults (21-24 years) amateur participants of different sports (i.e., football, basketball, volleyball...) declared that the most important motive for their sport participation was health, followed by social/enjoyment and skill development [13]. In another study, young adults declared that their motives to be active physically were mastery (become more skilled) and physical fitness [14]. Therefore, many youngsters, who don't have the necessary skills (physical, technical or tactical) to pursue a professional career in football, continue to play during their twenties and their thirties (some even into their forties) because they want to stay healthy and fit while they practice the sport that they enjoy. Almost in every country, there exist many regional leagues with thousands of players whose drive to play football is their love for the game, but also to maintain an active lifestyle and the broad range of physiological effects that have been linked to football practice $[15,16]$. The question that this study brings is: can football practice at the amateur level help players meet the criteria required to be considered physically active individuals? [1, 2, 3].

Over the last decade, there has been a growing interest in assessing individuals' physical activity levels precisely. Wearable devices like accelerometers are becoming more and popular to objectively monitor and assess free-living physical activity in all type of individuals (i.e., children, adolescents, adults, elderly, athletes, students...), because they can help overcome many of the limitations of most of the other methods used such as questionnaires or pedometers [17]. Accelerometers can provide objective, time-stamped data of the intensity, frequency and duration of any complete program of physical activity performed without disturbing the individuals who wear those devices because of their small size [18]. To our knowledge, there are no published studies which have used accelerometers to assess the impact of amateur football practice in the players.

Based on the aforementioned, the main goal of the present study was to obtain objective measures of the impact of a complete pre-season (5 weeks) in a group of amateur football players' physical activity parameters using accelerometers. The first hypothesis was that this group of athletes will meet the requirement of " 150 minutes a week of MVPA physical activity". The second hypothesis was that the pre-season will be rated as "somewhat hard". The final hypothesis was that the quadriceps and the hamstrings will be the most demanded muscles while practicing football.

\section{Materials and methods}

\section{Participants}

17 amateur football players $(24.47 \pm 4.53$ years $)$ agreed to participate. They belonged to the same team enrolled in the Spanish division VI football league. Prior to study enrolment, participants underwent a physical examination by a medical staff to validate their health 
status. They were considered healthy if they had no injuries for at least eight weeks prior to the evaluation. Years of football practice, age, height, weight, and the sum of six skinfolds (abdominal, suprailiac, tricipital, subescapular, thigh, and medial leg) using a skinfold caliper (Holtain ${ }^{\circledR}, \mathrm{UK}$ ) were determined prior to the study. Participants' characteristics are showed in Table 1. Unfortunately, two dropouts occurred during the time of the study due to injuries. These participants were not included in data analysis.

Table 1. Anthropometric measures.

\begin{tabular}{lcc}
\hline & M & SD \\
\hline Age & 24.47 & 4.53 \\
Height & 1.79 & 0.05 \\
Weight & 75.78 & 11.44 \\
Sum of 6 skinfolds & 69.99 & 24.83 \\
Years of football practice & 16.94 & 4.97 \\
\hline \multicolumn{2}{l}{ Note: M = mean; SD = standard deviation }
\end{tabular}

\section{Procedure}

First, permission to conduct the study was obtained from the researchers' University Human Ethics Committee. Second, the research project was presented to the soccer team's manager, coach and players, and written permission was obtained from all of them. Third, all participants followed the same weekly football training program, which constituted the teams' pre-season. It began after the summer off-period and it included three sessions (60 min each) per week during 5 weeks. All sessions focused on conditioning, technical and tactical skills, preparing the players for the incoming season. In every training session each player wore an accelerometer.

\section{Measurements}

\section{Accelerometers}

Actigraphs wGT3X+ (Actigraph, Pensacola, Fl, USA) were initialized to provide objective measurements of physical activity. Triaxial accelerometers perceive acceleration in three planes: vertical, horizontal and perpendicular. Participants were asked to wear the accelerometer on the right hip for the total duration of each training practice. Raw data collected by the accelerometer was analyzed using Actilife software 6.11.9 (Actigraph, Pensacola, Fl, USA).

\section{Rate of Perceived Exertion (RPE)}

Morgan and Borg [18] found that during prolonged work intervals the rate of RPE change is a responsive indicator of fatigue. They found a linear relationship between perceptual factors and physiological (oxygen uptake and heart rate) or physical (work rate) parameters in their 620 scale [20]. Football training includes physical, psychological, technical, and tactical components, and the overall workout can be very demanding [21]. The 6-20 Borg scale was explained to all participants prior to the beginning of the study. It remained in the participants' view throughout every session, and they were asked to rate their perceived exertion at the end of each one. Response range was from 6: "very, very light" to 20: "very, very hard".

\section{Total Quality Recovery (TQR)}

Success in sport is a balance between training to achieve peak performance and resting to avoid the negative consequences of overtraining. The TQR scale [22] was developed matching the 6-20 RPE scale to assess athletes' self-perception of recovery prior to training 
and/or competition, increasing their self-awareness. In the present study, it was used prior to every scheduled practice, when each participant was asked: how recuperated are you? Response range was from 6: "very, very poor recovery" to 20: "very, very good recovery".

\section{Local Ratings of Perceived Exertion (LRPE)}

Based on Borg's RPE scale, Nilsson, Csergö, Gullstrand, Tveit, and Refnes [23] validated a modified version to estimate athletes' perceived exertion in specific body parts (muscles). At the end of each one of the training session, every participant was given an anatomical diagram showing anterior and posterior views of the body. They were asked to identify the areas (muscle groups) they felt had been exerted during practice and give a percentage (for a total of $100 \%)$ to each area.

\section{Data analysis}

As mentioned earlier, raw data obtained from the accelerometers was analyzed using Actilife software 6.0 (Actigraph, Pensacola, Fl, USA). It was converted and extracted into Excel (Microsoft, San Diego, Ca, USA) files. Finally, all data were analyzed using SPSS 22.0 version (IBM, Chicago, IL, USA). Descriptive and correlational statistics were conducted.

\section{Results}

The goal of the present study was to obtain objective measures of the impact of a complete pre-season (5 weeks) in a group of amateur football players' physical activity parameters using accelerometers. Table 2 shows the mean global scores registered. Every football player spent an average $54.86 \%$ of each training session at MVPA level (32.91 minutes), $18.17 \%$ at vigorous level (10.90 minutes), the average number of METs was 3.78, the average number of steps was 4556.78 , and consumed an average of $267.10 \mathrm{kcal}$. Finally, participants' TQR mean score was 14.47, "good recovery", and RPE's score was 12.80, "somewhat hard".

Table 2. Mean global scores per training session.

\begin{tabular}{ccc}
\hline & M & SD \\
\hline MVPA & $54.86 \%$ & 3.07 \\
Vigorous & $18.17 \%$ & 3.52 \\
Kcal & 267.10 & 34.39 \\
METs & 3.78 & .23 \\
Steps & 4556.78 & 375.57 \\
TQR & 14.47 & 1.15 \\
RPE & 12.80 & .64 \\
\hline
\end{tabular}

Table 3 includes all scores in every training session. Analysis of LRPE revealed that quadriceps (29.41\%) and hamstrings (25.61) received the highest ratings from all participants (Table 4). Gastrocnemius (18.31\%) and adductor longus (11.84\%) were also highly mentioned, followed by lumbars (6.15\%), Soleus (3.89\%), Latissimus dorsi (3.78\%) and foot muscles (2.87\%). Peroneus $(0.30 \%)$ and gluteus $(0.30 \%)$ were scarcely mentioned. 
Table 3. Scores in every training session.

\begin{tabular}{|c|c|c|c|c|c|c|c|c|c|c|c|c|c|c|}
\hline & Session 1 & Session 2 & Session 3 & Session 4 & Session 5 & Session 6 & Session 7 & Session 8 & Session 9 & Session 10 & Session 11 & Session 12 & Session 13 & Session 14 \\
\hline \multirow{2}{*}{ TQR } & 15.68 & 13.68 & 14.06 & 13.13 & 15.71 & 14.42 & 14.35 & 14.25 & 14.50 & 13.80 & 13.58 & 14.35 & 13.64 & 14.86 \\
\hline & 2.62 & 3.19 & 2.46 & 2.35 & 2.46 & 2.02 & 2.34 & 2.59 & 2.46 & 1.97 & 2.23 & 2.61 & 2.23 & 2.44 \\
\hline \multirow[t]{2}{*}{ RPE } & 13.43 & 12.56 & 13.56 & 14.80 & 11.07 & 13.78 & 12.42 & 14.41 & 14.33 & 11.73 & 11.16 & 12.14 & 12.57 & 11.06 \\
\hline & 1.59 & 1.71 & 1.96 & 2.11 & 2.97 & 1.76 & 1.78 & 1.88 & 1.37 & 1.43 & 1.52 & 1.09 & 1.22 & 1.75 \\
\hline \multirow[t]{2}{*}{ Kcal } & 313.39 & 259.83 & 339.46 & 263.80 & 268.88 & 289.22 & 231.06 & 242.76 & 260.01 & 255.86 & 236.75 & 290.93 & 319.48 & 190.08 \\
\hline & 49.87 & 60.41 & 71.49 & 82.23 & 55.50 & 69.00 & 59.42 & 121.06 & 88.60 & 56.86 & 52.98 & 86.79 & 84.81 & 35.58 \\
\hline \multirow[t]{2}{*}{ METs } & 4.50 & 4.06 & 4.32 & 3.52 & 3.68 & 4.17 & 3.36 & 3.44 & 3.70 & 3.65 & 3.52 & 3.96 & 4.23 & 2.94 \\
\hline & .48 & .59 & .44 & .42 & .33 & .66 & .39 & .87 & .77 & .41 & .30 & .75 & .76 & .25 \\
\hline \multirow[t]{2}{*}{$\%$ Sedentary } & 9.65 & 12.11 & 10.05 & 18.43 & 14.39 & 14.76 & 25.43 & 28.95 & 19.52 & 15.37 & 20.24 & 18.40 & 12.54 & 36.33 \\
\hline & 3.66 & 4.42 & 4.24 & 6.29 & 5.14 & 8.48 & 8.92 & 11.00 & 5.33 & 3.83 & 3.34 & 11.69 & 7.61 & 7.36 \\
\hline \multirow[t]{2}{*}{ \% Light } & 21.82 & 27.72 & 26.49 & 29.79 & 32.29 & 22.09 & 30.58 & 25.68 & 27.90 & 30.07 & 31.39 & 24.98 & 19.91 & 24.96 \\
\hline & 6.23 & 6.73 & 5.24 & 4.44 & 7.16 & 7.36 & 5.40 & 6.86 & 6.60 & 4.55 & 3.50 & 4.56 & 6.90 & 4.73 \\
\hline \multirow[t]{2}{*}{ \%Moderate } & 44.53 & 38.26 & 37.74 & 36.44 & 34.47 & 39.82 & 24.06 & 25.49 & 33.03 & 38.40 & 26.91 & 33.64 & 47.94 & 25.92 \\
\hline & 7.15 & 6.36 & 6.54 & 6.11 & 6.08 & 9.94 & 7.48 & 6.86 & 4.99 & 5.81 & 7.11 & 9.40 & 11.46 & 5.84 \\
\hline \multirow[t]{2}{*}{ \%Vigorous } & 21.49 & 20.99 & 23.15 & 14.77 & 16.75 & 22.36 & 17.91 & 17.50 & 18.00 & 14.14 & 21.03 & 20.34 & 18.70 & 11.51 \\
\hline & 7.56 & 10.10 & 6.30 & 6.41 & 5.63 & 9.74 & 5.17 & 14.86 & 9.80 & 6.12 & 6.69 & 8.72 & 9.51 & 2.84 \\
\hline \multirow[t]{2}{*}{ \%Very Vig. } & 2.49 & .90 & 2.54 & .54 & 2.08 & .95 & 1.99 & 2.36 & 1.53 & 2.00 & .40 & 2.61 & .88 & 1.25 \\
\hline & 1.80 & 1.30 & 3.82 & .82 & 1.31 & .88 & 2.81 & 1.51 & 1.04 & 4.08 & .40 & 3.38 & .92 & .69 \\
\hline \multirow[t]{2}{*}{$\%$ MVPA } & 68.52 & 60.16 & 63.44 & 51.76 & 53.31 & 63.14 & 43.97 & 45.36 & 52.57 & 54.54 & 48.35 & 56.60 & 67.54 & 38.69 \\
\hline & 6.97 & 8.58 & 6.56 & 5.26 & 5.79 & 10.68 & 5.78 & 9.90 & 9.04 & 3.83 & 3.27 & 11.81 & 13.71 & 4.41 \\
\hline \multirow[t]{2}{*}{ Steps } & 5001.68 & 4412.47 & 5172.06 & 4587.53 & 4631.71 & 5159.57 & 3882.07 & 4119.16 & 4436.66 & 4498.46 & 4436.83 & 4728.15 & 5561.92 & 3356.06 \\
\hline & 404.29 & 863.48 & 826.03 & 681.64 & 580.64 & 1170.83 & 488.03 & 1325.19 & 1046.80 & 482.53 & 705.96 & 1258.44 & 1439.98 & 297.68 \\
\hline
\end{tabular}

Note: scores are presented in mean \pm standard deviation. 
Table 4. LRPE (\%) in every training session.

\begin{tabular}{|c|c|c|c|c|c|c|c|c|c|c|c|c|c|c|c|}
\hline & 1 & 2 & 3 & 4 & 5 & 6 & 7 & 8 & 9 & 10 & 11 & 12 & 13 & 14 & Average \\
\hline Latissimus Dorsi & - & 4.11 & 3.75 & 2.5 & 7.85 & 1.78 & 4.28 & 5.45 & 5.0 & - & 7.27 & 2.14 & 2.85 & 6.0 & 3.78 \\
\hline Lumbars & 5.88 & 2.94 & 1.56 & 1.25 & 7.14 & 11.42 & 9.28 & 5.45 & 2.5 & 3.57 & 9.09 & 7.14 & 7.85 & 11.0 & 6.15 \\
\hline Gluteus & 0.58 & - & 1.56 & - & - & 2.14 & - & - & - & - & - & - & 0.71 & - & 0.30 \\
\hline Quadriceps & 30.58 & 31.47 & 27.18 & 35.62 & 30.0 & 19.28 & 19.64 & 23.18 & 31.66 & 27.5 & 24.09 & 29.28 & 32.85 & 49.5 & 29.41 \\
\hline Hamstrings & 27.64 & 39.41 & 29.06 & 29.68 & 27.5 & 18.21 & 13.57 & 20.9 & 25.0 & 23.92 & 21.81 & 20.71 & 23.21 & 38.0 & 25.61 \\
\hline Adductor Longus & 15.88 & 8.23 & 8.12 & 7.5 & 3.57 & 2.85 & 15.0 & 9.09 & 13.33 & 17.85 & 15.0 & 21.07 & 15.71 & 22.5 & 11.84 \\
\hline Gastrocnemius & 15.29 & 10.88 & 27.5 & 22.18 & 21.78 & 32.85 & 21.78 & 16.81 & 13.33 & 12.85 & 20.45 & 15.35 & 10.35 & 15.0 & 18.31 \\
\hline Soleus & 4.11 & 1.17 & - & - & 0.71 & 7.85 & 4.28 & 13.63 & - & 3.57 & 2.27 & 4.28 & 5.71 & 7.0 & 3.89 \\
\hline Peroneus Longus & - & - & 1.25 & 1.25 & 0.71 & - & - & - & 0.83 & - & - & - & - & 1.0 & 0.36 \\
\hline Foot Muscles & - & - & - & - & - & 3.57 & 12.14 & 5.45 & 8.33 & 10.71 & - & - & - & - & 2.87 \\
\hline
\end{tabular}


To clarify the findings in every training session, only METS, MVPA, TQR and RPE were included in figure 1. It can be observed that all of them followed an oscillatory pattern, which could be considered normal in pre-season training.

Figure 1. METs, MVPA, TQR and RPE scores in every training session.

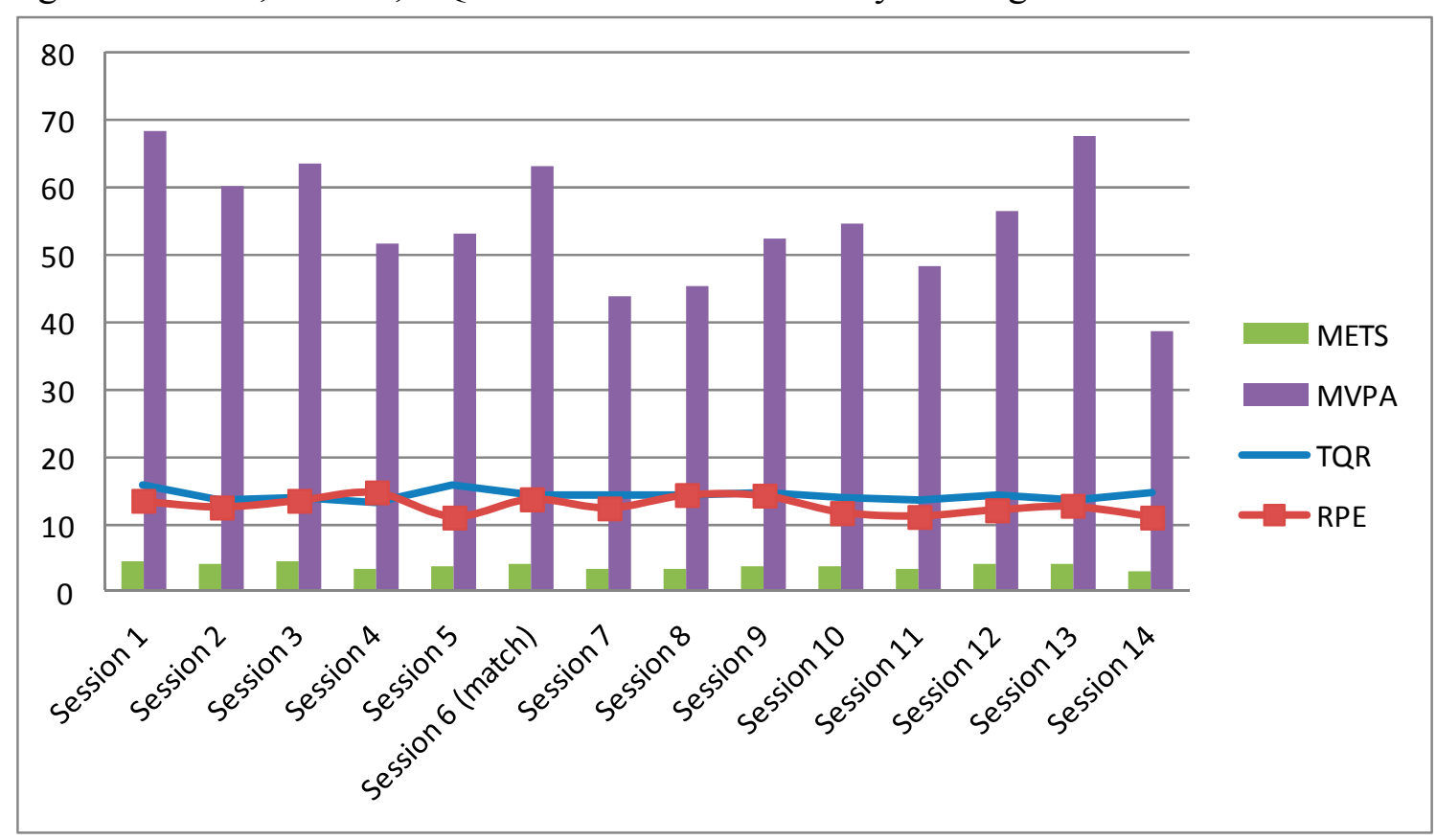

Finally, correlation analyses were conducted to assess the different connections among variables. Strong correlations were found only between MVPA, METs and Kcal (table 5).

Table 5. Correlations among variables.

\begin{tabular}{lccccc}
\hline & 1 & 2 & 3 & 4 & 5 \\
\hline 1. Kcal & 1 & $.895^{* *}$ & .305 & .228 & $.703^{*}$ \\
2. METs & $.895^{* *}$ & 1 & .265 & .522 & $.867^{* *}$ \\
3. TQR & .305 & .265 & 1 & -.127 & -.038 \\
4. RPE & .228 & .522 & -.127 & 1 & .538 \\
5. MVPA & $.703^{*}$ & $.867^{* *}$ & -.038 & .538 & 1 \\
\hline *p $<0.05 ;{ }^{* *} p<0.01$ & & & &
\end{tabular}

\section{Discussion}

The main goal of the present study was to obtain objective measures of the impact of a complete pre-season (5 weeks) in a group of amateur football players' physical activity parameters using accelerometers. The first hypothesis was that this group of athletes will meet the requirement of "150 minutes a week of MVPA physical activity". The second hypothesis was that the pre-season will be rated as "somewhat hard". The final hypothesis was that the quadriceps and the hamstrings will be the most demanded muscles while practicing football. The results confirmed only the second and third hypotheses.

The first hypothesis was that this group of athletes will meet the requirement of " 150 minutes a week of MVPA physical activity". Results obtained showed that this group of amateur football players spend $54.86 \%$ of each 60 -minute training session working al MVPA level. This means that each player spent 33.31 minutes at this level during each 60-minute session, and a total of 100.33 minutes every week ( 3 training sessions per week). Therefore, this group of amateur football players did not meet the requirements of the international organizations 
$[1,2,3]$ to obtain health benefits from their physical activity program: amateur football. This finding could be considered noteworthy because there are thousands, or even millions, of adults worldwide who play and train football at an amateur level for years to be fit and healthy. They should be aware that their weekly training load is not enough to help them meet the requirements of an active and healthy lifestyle. Results indicate that they need more practice time (90-minute sessions) or more sessions. Unfortunately, there are no published studies on amateur football or fitness football to compare. On the other hand, vigorousintensity physical activity has been found more beneficial for health than moderate-intensity activities such as walking [4, 6], and results from the present study have showed that amateur football training can provide moderate-to-vigorous, vigorous and very vigorous workout intensities.

The second hypothesis was that the pre-season training program will be rated as "somewhat hard" by the players. Results support this hypothesis since participants rated the program 12.80 in the 6-20 Borg scale [19]. This was an expected result. Amateur football players enjoy practice, because they feel connected to the sport, but it cannot be too demanding or they will quit. For these individuals football is a hobby, not a profession, and their motivation to be involved is primary linked to health, mastery and enjoyment $[13,14]$. If practice becomes too strenuous, it also becomes less fun. The football players that participated in the present study had been playing football for an average of 17 years. This means that they started very young and continue playing and competing, although they will never make a living out of football. Their motives should be similar to the ones found in amateur footballers: health and enjoyment [13] and active adults: mastery and physical fitness [14]. Therefore, practice should never be too strenuous. This is in line with the results obtained in the TQR scale. Participants were asked prior to each practice how recuperated they were, and the mean response was 14.47, which means "good recovery" in the 6-20 scale [22]. Again, participants felt well before practice, which could mean that were ready and motivated. They need those feelings to continue practicing and playing at an amateur level, because they have to fit football into a tight schedule of work, family and friends.

The final hypothesis was that the quadriceps and the hamstrings will be the most demanded muscles and results confirmed it. Previous research has showed that the most exerted muscles while playing and practicing football are the quadriceps and the hamstrings [24]. They are necessary for actions like kicking, running, sprinting or jumping.

The present study holds several limitations. First, the number of participants could be considered limited. However, they belonged to the same football team and help obtain accurate data. Future studies should be conducted in larger samples. Second, a limited number of performance variables were assessed. Other variables such as heart rate or lactate should be connected to MVPA scores to obtain a wider view on amateur football players' health parameters. Finally, participants were only males. Future studies should be conducted in women football players to compare results.

\section{Conclusions}

The most important motive for sport participation among amateur athletes seems to be health, followed by enjoyment. However, an amateur football pre-season, which included 60 -minutes sessions, did not help players meet the requirements to obtain health benefits from their physical activity program. To meet them, they need more practice time (90-minute sessions) or more sessions.

\section{References}

1. Department of Health Physical Activity Health Improvement and Protection. Start active, stay active: a report on physical activity for health from the four home Countries' chief medical officers. London: Department of Health, 2011

2. Karolinska Institute. IPAQ home page, 2011. www.ipaq.ki.se: accessed Oct. 23rd, 2016. 
3. World Health Organization. Physical activity and adults, 2011. http://www.who.int/dietphysicalactivity/factsheet_adults/en/ : accessed Oct. 24th, 2016.

4. Hallal, P.C.; Andersen, L.B.; Bull, F.C.; Guthold, R.; Haskell, W.; Ekelund, U. Global physical activity levels: surveillance progress, pitfalls, and prospects. Lancet, 2012, 380(9838), 247-257.

5. I.-M. Lee, E.J.; Shiroma, F.; Lobelo, J. et al. Effect of physical inactivity on major noncommunicable diseases worldwide: an analysis of burden of disease and life expectancy. Lancet, 2012, 380(9838), 219-229

6. Knuth, A.G.; Hallal, P.C. Temporal trends in physical activity: a systematic review. J Phys Act Health, 2009, 6(5), 548.

7. Hammami, A.; Chamari, K.; Slimani, M.; Shephard, R. J.; Yousfi, N.; Tabka, Z.; Bouhlel, E. Effects of recreational soccer on physical fitness and health indices in sedentary healthy and unhealthy subjects. Biol Sport, 2016, 33(2), 127-137.

8. Bennike, S.; Wikman, J.M.; Ottesen, L.S. Football Fitness-a new version of football? A concept for adult players in Danish football clubs. Scand J Med Sci Sports, 2014, 24(S1), 138-146.

9. Čović, N.; Alić, H.; Manić, G. Effects of recreational soccer on health status improvement. Sport Sci, 2016, 18.

10. av Fløtum, L.; Ottesen, L.S.; Krustrup, P.; Mohr, M. Evaluating a nationwide recreational football intervention-recruitment, attendance, adherence, exercise intensity and health effects, 2016. http://dx.doi.org/10.1155/2016/7231545

11. Krustrup, P.; Bangsbo, J. Recreational football is effective in the treatment of noncommunicable diseases. Brit J Sport Med, 2015.

12. Milanović, Z.; Pantelić, S.; Čović, N.; Sporiš, G.; Krustrup, P. Is Recreational Soccer Effective for Improving VO2max? A Systematic Review and Meta-Analysis. Sports Med, 2015, 45(9), 1339-1353.

13. Caglar, E.; Canlan, Y.; Demir, M. Recreational exercise motives of adolescents and young adults. J Hum Kinet, 2009, 22, 83-89.

14. Aaltonen, S.; Rottensteiner, M.; Kaprio, J.; Kujala, U.M. Motives for physical activity among active and inactive persons in their mid-30s. Scand J Med Sci Sports, 2014, 24(4), 727-735.

15. Bangsbo, J.; Hansen, P.R.; Dvorak, J.; Krustrup, P. Recreational football for disease prevention and treatment in untrained men: a narrative review examining cardiovascular health, lipid profile, body composition, muscle strength and functional capacity. Brit $J$ Sport Med, 2015, 49(9), 568-576.

16. Parnell, D.; Cope, E.; Bailey, R.; Krustrup, P.; Curran, K. Football and physical health: what do we know? Sport in Society, 2016, 1-21.

17. Aparicio-Ugarriza, R.; Mielgo-Ayuso, J.; Benito, P.J.; Pedrero-Chamizo, R.; Ara, I.; González-Gross, M.; EXERNET Study Group. Physical activity assessment in the general population; instrumental methods and new technologies. Nutr Hosp, 2015, 31(3), 219-226.

18. Sanders, T.; Cliff, D.P.; Lonsdale, C. Measuring adolescent boys' physical activity: bout length and the influence of accelerometer epoch length. PloS one, 2014, 9(3), e92040.

19. Morgan, W.P.; Borg, G.A.V. Perception of effort in the prescription of physical activity. In The humanistic and mental health aspects of sports, exercise and recreation; Craig, $\mathrm{T}$. ed.; American Medical Association: Chicago, IL, 1976, pp. 126-139.

20. Borg, G. Borg's perceived exertion and pain scales. Human Kinetics: Leeds, UK, 1998.

21. Mohr, M.; Krustrup, P.; Bangsbo, J. Match performance of high- standard soccer players

with special reference to development of fatigue. J Sports Sci. 2004, 21(7), 519-528, 2003.

22. Kenttä, G.; Hassmén, P. Overtraining and recovery. Sports Med, 1998, 26(1), 1-16. 
23. Nilsson, J.; Csergö, S.; Gullstrand, L.; Tveit, P.; Refnes, P.E. Work-time profile, blood lactate concentration and rating of perceived exertion in the 1998 Greco-Roman wrestling World Championship. J Sports Sci. 2002, 20(11), 939-45.

24. Ruas, C.V.; Minozzo, F.; Pinto, M.D.; Brown, L.E.; Pinto, R.S. Lower-extremity strength ratios of professional soccer players according to field position. $J$ Strength Cond Res, 2015, 29(5), 1220-1226.

(C) 2016 by the authors; licensee Preprints, Basel, Switzerland. This article is an open access article distributed under the terms and conditions of the Creative Commons by Attribution (CC-BY) license (http://creativecommons.org/licenses/by/4.0/). 